Letters to the Editor

\title{
Retention Behavior of Anionic Complexes of Cobalt(III) in Reversed-Phase HPLC. Importance of Local Charge Distribution within the Complex
}

\author{
Hiroshi Niwa, Takashi Yasui, Akio Yuchi, Hiromichi Yamada and Hiroko Wada ${ }^{\dagger}$ \\ Department of Applied Chemistry, Nagoya Institute of Technology, Gokiso, Showa, Nagoya 466, Japan
}

Keywords Ion-pair reversed-phase high-performance liquid chromatography, sulfonated 2-(2-pyridylazo)-1-naphthols, cobait(III) complex, mixed-ligand complex

Tridentate azo compounds, forming stable and deeply colored metal complexes, have been used as precolumn derivatizing reagents for HPLC separation and determination of metal ions. When ligands which can be dianions upon full deprotonation (the neutral form is generally expressed as $\mathrm{H}_{2} \mathrm{~L}$ ) are used, the resulting complexes are anionic. The retention can be modified by changing the types and concentrations of the counter cation or of the organic modifier in ion-pair reversedphase HPLC or ion-interaction chromatography. ${ }^{1} \mathrm{~A}$ typical ligand used is $o, o^{\prime}$-dihydroxyazobenzene. The trivalent metal complexes, $\left[\mathrm{M}^{\mathrm{II}} \mathrm{L}_{2}\right]^{-}(\mathrm{M}: \mathrm{Co}, \mathrm{Al}, \mathrm{Fe})$, were appreciably retained and easily separated in the reversed-phase HPLC system in the presence of an ionpairing reagent such as tetrabutylammonium bromide (TBABr). ${ }^{2-5}$ The divalent metal complexes, $\left[\mathrm{M}^{\mathrm{II}} \mathbf{L}_{2}\right]^{2-}$, on the other hand, were dissociated in the column and were not detected.

In a series of studies on precolumn derivatizing reagents, we have examined several sulfonated azo compounds, which form metal complexes of the same charges as those of $o, o^{\prime}$-dihydroxyazobenzene. ${ }^{6}$ The retention of divalent metal complexes $\left[\mathrm{M}^{\mathrm{II}} \mathrm{L}_{2}\right]^{2-}$ and a free ligand $\mathrm{HL}^{-}$increased with an increase in concentration of the ion-pairing reagent. The retention of a cobalt(III) complex, $\left[\mathrm{CoL}_{2}\right]$, on the other hand, was exceptionally small and exhibited a remarkable contrast to that of the $o, o^{\prime}$-dihydroxyazobenzene complex of $\mathrm{Co}$ (III).

The difference in retention between these complexes may be ascribed to a difference in nature of the negative charges on the two ligands. $o, o$-Dihydroxyazobenzene coordinates to metal ions using two deprotonated hydroxy groups as well as one neutral nitrogen atom (hereafter, such ligands are expressed as $\mathrm{H}_{2} \mathrm{dh}$ ), while sulfonated azo compounds use only one deprotonated hydroxy group and two nitrogen atoms and have a sulfonate group at a peripheral position $\left(\mathrm{H}_{2} \mathrm{mh}\right)$. To further verify this point, we have examined the chromatographic behavior of ternary systems consisting

t To whom correspondence should be addressed.

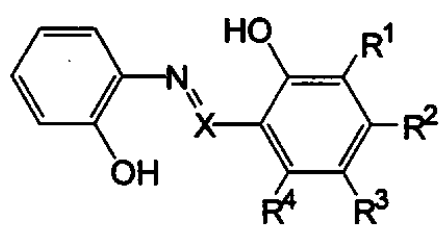

$$
\mathrm{S}^{1}: \mathrm{X}=\mathrm{N} ; \mathrm{R}^{1}, \mathrm{R}^{2}, \mathrm{R}^{3}, \mathrm{R}^{4}=\mathrm{H}
$$$$
S^{2}: X=C H ; R^{1}, R^{2}=\text { phenylene; } R^{3}, R^{4}=H
$$$$
S^{3}: X=C H ; R^{1}, R^{2}=H ; R^{3}, R^{4}=\text { phenylene }
$$

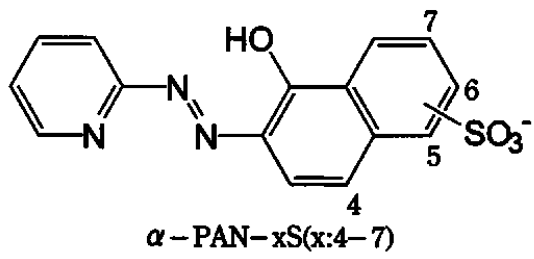

Scheme 1 Structural formulas of derivatizing reagents.

of $\mathrm{Co}(\mathrm{III}), \mathrm{H}_{2} \mathrm{dh}$ and $\mathrm{H}_{2} \mathrm{mh}$ in this work.

\section{Experimental}

The two types of derivatizing reagents used in this study are shown in Scheme 1. Sulfonated azo compounds $(\alpha-P A N-x S ; x$ denotes the position of a sulfonate group on the naphthalene ring) were used as $\mathbf{H}_{2} \mathbf{m h}$, whereas $o, o^{\prime}$-dihydroxyazobenzene $\left(\mathrm{S}^{1}\right)$, 1-hydroxy-2naphthylmethylidene-2-hydroxyphenylamine $\left(S^{2}\right)$, and 2-hydroxy-1-naphthylmethylidene-2-hydroxyphenylamine $\left(S^{3}\right)$ were used as $H_{2} d h$. The ligand $S^{1}$ was adopted, since its performance as a derivatizing reagent has been well documented. ${ }^{2-5}$ To adjust the lipophilicity of ligands for rigorous comparison, the Schiff bases were also adopted, since the corresponding azo compounds may form linkage isomers to make the chromatogram more complicated. ${ }^{7}$

Sulfonated 2-(2-pyridylazo)-1-naphthol derivatives were prepared as described previously. ${ }^{8,9}$ Two Schiff 
bases, $S^{2}$ and $S^{3}$, were synthesized by the condensation of o-aminophenol with 1-hydroxy-2-naphthaldehyde or 2hydroxy-1-naphthaldehyde. ${ }^{10}$ Other reagents including 1,2-dihydroxyazobenzene were reagent-grade and were used without further purification.

Sample solutions of ternary systems including cobalt and one from each of two ligand groups were prepared as follows. An ethanol solution of $S^{1}\left(2.5 \times 10^{-4} \mathrm{M}, 1 \mathrm{ml}\right)$ was mixed with an aqueous acetonitrile solution of $\mathrm{H}_{2} \mathrm{mh}$ $\left(1 \times 10^{-4} \mathrm{M}, 1 \mathrm{ml}\right)$, followed by the addition of an acetate buffer $(0.1 \mathrm{M}, \mathrm{pH} 6,1 \mathrm{ml})$ and an aqueous cobalt nitrate solution $\left(1 \times 10^{-4} \mathrm{M}, 1 \mathrm{ml}\right)$. In the systems including $\mathrm{S}^{2}$ or $S^{3}$ instead of $S^{1}$, the amount of a Schiff base was increased by 20 times and the final mixture was heated at $80^{\circ} \mathrm{C}$ for $15 \mathrm{~min}$, in order to compensate their lower reactivities.

The chromatographic systems were the same as described previously. ${ }^{6}$ The acetonitrile-water $(60: 40$, $\mathrm{v} / \mathrm{v})$ containing $\mathrm{TBABr}\left(10^{-2} \mathrm{M}\right)$ and acetate buffer $\left(\mathrm{pH} 5.0,10^{-3} \mathrm{M}\right)$ was used as an eluent at a flow rate of $0.8 \mathrm{ml} / \mathrm{min}$ at $40^{\circ} \mathrm{C}$. Separation was carried out on an Inertsil ODS-2 (4.6 mm i.d. $\times 250 \mathrm{~mm}, 5 \mu \mathrm{m})$ column.

\section{Results and Discussion}

\section{Evidence for a mixed-ligand complex of $\mathrm{Co}(\mathrm{III})$}

Figure 1 shows the chromatograms for the ligand $\mathbf{H}_{2} \mathrm{dh}$ (a), the binary systems of $\mathrm{Co} / \mathrm{H}_{2} \mathrm{dh}$ (b) and $\mathrm{Co} / \mathrm{H}_{2} \mathrm{mh}$ (c), and the ternary system of $\mathrm{Co} / \mathrm{H}_{2} \mathrm{dh} / \mathrm{H}_{2} \mathrm{mh}$ (d) under the same conditions, where $S^{2}$ and $\alpha$-PAN-7S were adopted as $\mathrm{H}_{2} \mathrm{dh}$ and $\mathrm{H}_{2} \mathrm{mh}$, respectively. The Schiff base was not stable enough in solutions and decomposed to give a few small peaks along with its main peak. The Co/ $\mathrm{H}_{2} \mathrm{dh}$ system showed an additional peak at an elution time of $30.5 \mathrm{~min}$, which was ascribed to its cobalt complex. The $\mathrm{Co} / \mathrm{H}_{2} \mathrm{mh}$ system also gave two peaks assigned to a free ligand and its cobalt complex. Since the acetonitrile contents were increased compared with the optimized conditions ${ }^{6}$, in order to obtain all the peaks of a $\mathrm{Co} / \mathrm{H}_{2} \mathrm{dh}$ system within a reasonable time, the cobalt complex of a $\mathrm{Co} / \mathrm{H}_{2} \mathrm{mh}$ system was eluted without any retention. Compared with all the peaks appearing in these three chromatograms, the ternary system of $\mathrm{Co} /$ $\mathrm{H}_{2} \mathrm{dh} / \mathrm{H}_{2} \mathrm{mh}$ exhibited one extra peak at $8.5 \mathrm{~min}$.

The spectrum of this species measured in the chromatographic system had the characteristics of both $\left[\mathrm{Co}(\mathrm{dh})_{2}\right]^{-}$and $\left[\mathrm{Co}(\mathrm{mh})_{2}\right]^{-}$. The retention of this complex increased with an increase in concentration of the ion-pairing reagent, and the addition of EDTA into the sample solution showed no effects on the chromatogram. All these findings confirmed the assignment of the new peak to the elution of the mixed-ligand complex of $\mathrm{Co}(\mathrm{III}),[\mathrm{Co}(\mathrm{dh})(\mathrm{mh})]$. Other systems of various combinations of cobalt, $\mathrm{H}_{2} \mathrm{dh}$, and $\mathrm{H}_{2} \mathrm{mh}$ as well as a rhodium(III)/S $/ \alpha$-PAN-7S system 'showed similar behaviors.
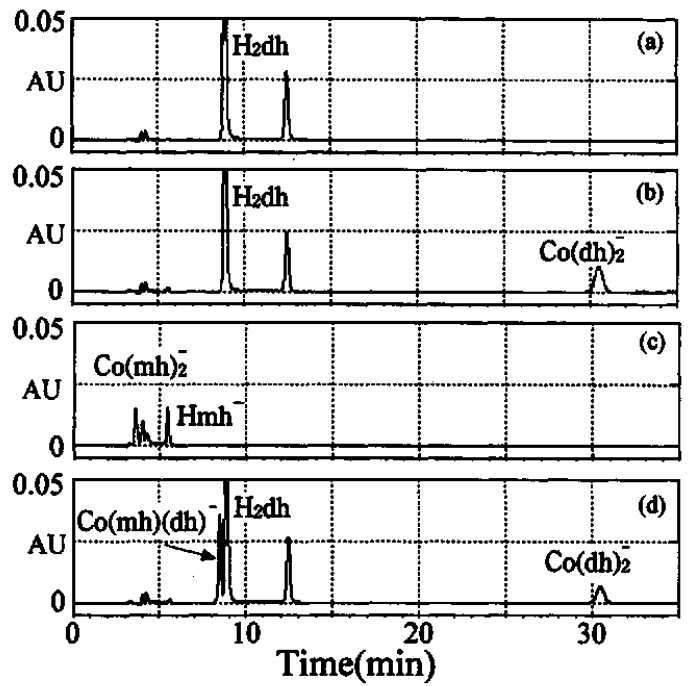

Fig. 1 Chromatograms for $\mathrm{H}_{2} \mathrm{dh}(\mathrm{a}), \mathrm{Co} / \mathrm{H}_{2} \mathrm{dh}(\mathrm{b}), \mathrm{Co} / \mathrm{H}_{2} \mathrm{mh}$ (c) and $\mathrm{Co} / \mathrm{H}_{2} \mathrm{dh} / \mathrm{H}_{2} \mathrm{mh}$ (d). $\mathrm{H}_{2} \mathrm{dh}, \mathrm{S}^{2} ; \mathrm{H}_{2} \mathrm{mh}, \boldsymbol{\alpha}-\mathrm{PAN}-7 \mathrm{~S}$. Mobile phase, acetonitrile-water $(60: 40, v / v)$ containing $10^{-2} \mathrm{M}$ TBABr and $10^{-3} \mathrm{M}$ aqueous acetate buffer of $\mathrm{pH} 5.0$. Flow rate, $0.8 \mathrm{ml} / \mathrm{min}$; column temperature, $40^{\circ} \mathrm{C}$.

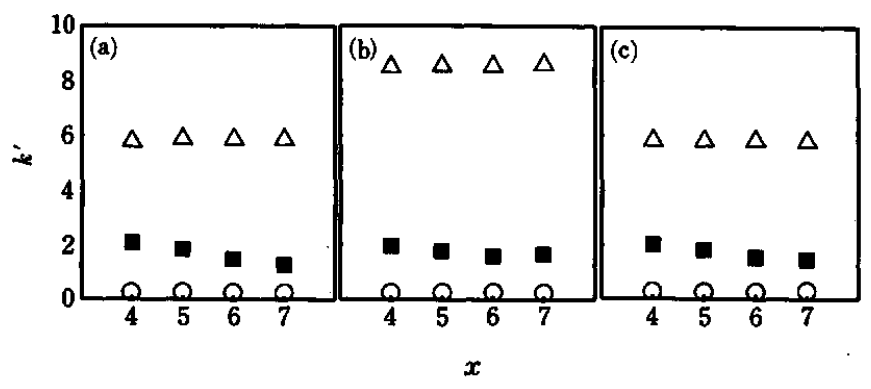

Fig. 2 Retention of Co(III) complexes in ternary systems. $\mathrm{H}_{2} \mathrm{dh}: \mathrm{S}^{1}$ (a); $\mathrm{S}^{2}$ (b); $\mathrm{S}^{3}$ (c). $\mathrm{H}_{2} \mathrm{mh}: \alpha-\mathrm{PAN}-x \mathrm{~S}(x=4-7)$. $\Delta,\left[\mathrm{Co}(\mathrm{dh})_{2}\right] ; \mathbf{D},[\mathrm{Co}(\mathrm{dh})(\mathrm{mh})] ; \mathrm{O},\left[\mathrm{Co}(\mathrm{mh})_{2}\right]$. Chromatographic conditions are the same as those in Fig. 1.

\section{Retention of the mixed-ligand complexes}

Figure 2 showed the retention of $\left[\mathrm{Co}(\mathrm{dh})_{2}\right]^{-}$, [Co$\left.(\mathrm{mh})_{2}\right]$, and $[\mathrm{Co}(\mathrm{dh})(\mathrm{mh})]$ for $\mathrm{S}^{1}(\mathrm{a}), \mathrm{S}^{2}(\mathrm{~b})$ and $\mathrm{S}^{3}(\mathrm{c})$ as $\mathrm{H}_{2}$ dh. In each system, the retention of $[\mathrm{Co}(\mathrm{dh})(\mathrm{mh})]^{-}$is much larger than that of $\left[\mathrm{Co}(\mathrm{mh})_{2}\right]^{-}$. Such a difference in retention, in spite of having the same net charge of $1-$, is explained as follows.

In $\left[\mathrm{Co}(\mathrm{mh})_{2}\right]$, the charge of $1+$ remains on the cobalt center by the coordination of two phenolate oxygen atoms and two negative charges are separately located on two sulfonate groups at peripheral positions. Upon the ion-pair formation, one of two negative charges can be neutralized by a counter cation in the mobile or stationary phase. The remaining charge separation between the metal center and a sulfonate group leads to unfavorable retention of this species (Scheme 2(a)). In $[\mathrm{Co}(\mathrm{dh})(\mathrm{mh})]^{-}$, on the other hand, the metal center is 


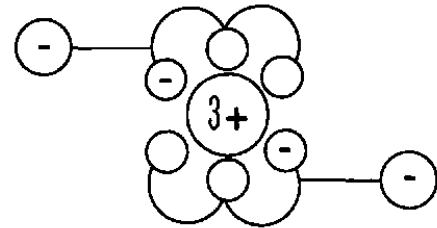

(a) $\left[\mathrm{CO}(\mathrm{mh})_{2}\right]$
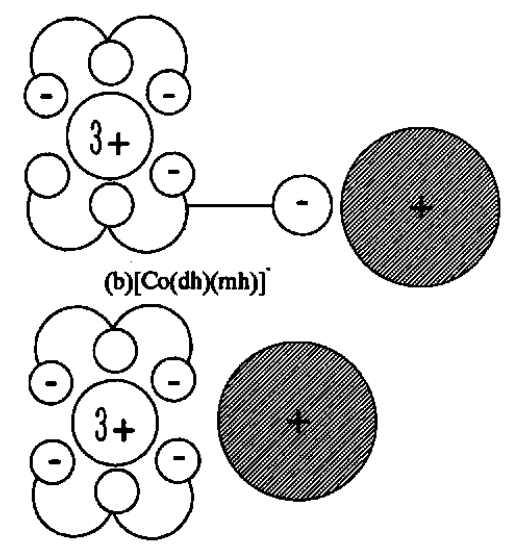

(c) $\left[\mathrm{Co}(\mathrm{dh})_{2}\right]$

Scheme 2 Models for ion-pairs of $\left[\mathrm{Co}(\mathrm{mh})_{2}\right]^{-},[\mathrm{Co}(\mathrm{dh})(\mathrm{mh})]^{-}$ and $\left[\mathrm{Co}(\mathrm{dh})_{2}\right]$ with a counter cation.

formally neutralized by three phenolate oxygen atoms. After the ion-pair formation between a counter cation and one sulfonate group, it is appreciably retained (Scheme 2(b)). The number of sulfonate groups is not critical; the divalent metal complexes, such as $\left[\mathrm{Ni}(\mathrm{mh})_{2}\right]^{2-}$ and $\left[\mathrm{Fe}(\mathrm{mh})_{2}\right]^{2-}$, are also appreciably retained. Further increase in retention is achieved by delocalization of $1-$ charge on the whole complex, as found for $\left[\mathrm{Co}(\mathrm{dh})_{2}\right]$ (Fig. 2(c)).

The specificity of $\left[\mathrm{Co}(\mathrm{mh})_{2}\right]^{-}$has also been pointed in ion-pair extraction systems; Kasahara and coworkers have demonstrated that the extractability of $\left[\mathrm{Co}^{\mathrm{II}} \mathrm{L}_{2}\right]^{-}$ [L'-: 2-(5-bromo-2-pyridylazo)-5-( $N$-propyl- $N$-sulfopropylamino)phenolate] is much lower than those of the corresponding cationic complex, $\left[\mathrm{Co}^{\mathrm{III}} \mathrm{L}_{2}\right]^{+}\left[\mathrm{L}^{-}: 2-(5-\right.$ chloro-2-pyridylazo)-5-diethylaminophenolate $].{ }^{11}$ The partition of the ion-pair of metal complexes is influenced not only by a net charge but also by a local chargedistribution.

This work was supported by a Grant-in-Aid for Scientific Research (No. 08455388) from the Ministry of Education, Science, Sports and Culture of Japan.

\section{References}

1. A. R. Timerbaev and O. M. Petruhkhin, Zh. Anal. Khim., 46, 213 (1991).

2. H. Hoshino and T. Yotsuyanagi, Chem. Lett., 1984, 1445.

3. H. Hoshino, K. Nakano and T. Yotsuyanagi, Analyst [London], 115, 133 (1990).

4. E. Kaneko, H. Hoshino, T. Yotsuyanagi, N. Gunji, M. Sato, T. Kikuta and M. Yuasa, Anal. Chem., 63, 2219 (1991).

5. H. Wada, T. Hakamata, K. Yasui, A. Yuchi and G. Nakagawa, Chem. Lett., 1991, 1571.

6. H. Niwa, T. Yasui, A. Yuchi, H. Yamada and H. Wada, Anal. Sci, 13, 137 (1997).

7. H. Pfitzner, Angew. Chem., Int. Ed. Engl., 11, 312 (1972).

8. R. G. Anderson and G. Nickless, Analyst [London], 93, 13 (1968).

9. K. Ohshita, H. Wada and G. Nakagawa, Anal. Chim. Acta, 140, 291 (1982).

10. R. J. Argauer and C. E. White, Anal. Chem., 36, 2141 (1964).

11. I. Kasahara, J. Ohgaki, K. Matui, K. Kanou, S. Taguchi and K. Goto, Nippon Kagaku Kaishi, 1986, 894.

(Received May 9, 1997)

(Accepted June 11, 1997) 